\title{
IS ADMINISTERED COMPETITION SUITABLE FOR DEALING WITH A PUBLIC HEALTH EMERGENCY? LESSONS FROM THE LOCAL HEALTHCARE SYSTEM AT THE CENTRE OF EARLY COVID-19 OUTBREAK IN ITALY
}

\author{
Federico Pennestri ${ }^{1}$, Antonio Gaudioso ${ }^{2}$, Anant Jani ${ }^{3}$, Elena Bottinelli ${ }^{1}$, Giuseppe Banfi ${ }^{1,4}$ \\ ${ }^{1}$ IRCCS Istituto Ortopedico Galeazzi, Milan, Italy \\ ${ }^{2}$ Cittadinanzattiva, Rome, Italy \\ ${ }^{3}$ Oxford Martin School, University of Oxford, Oxford, United Kingdom \\ ${ }^{4}$ Vita-Salute San Raffaele University, Milan, Italy
}

\begin{abstract}
SUMMARY
Objectives: The Lombardy Region, Italy, was the most severely affected by the COVID-19 outbreak. In absence of effective treatments and with basic hygiene measures made mandatory, Lombardy response to COVID-19 relied on its healthcare system characteristics, the administered competition or "quasi-market" model. The aim of the study was to review the strengths and weaknesses of Lombardy's response during the first wave of the COVID-19 epidemic, to explore whether the healthcare model influenced crisis management and describe which policies could help to contain future outbreaks. The results are expected to provide similar healthcare systems with lessons to avoid mistakes and learn from best practice.

Methods: Data for quantitative analyses on the performance of the Lombardy and Veneto Regions healthcare systems were derived from existing government sources including the Italian Civil Protection Agency and the Ministry of Health.

Results: Lombardian quasi-market model, traditionally characterized by a strong hospital network, was held responsible for many suboptimal outcomes. According to critics, years of disinvestments in community care resulted in a hospital overload. However, the same model was responsible for other positive outcomes which have been substantially neglected, such as the opportunity to test for effective containment treatments in a safe environment and rapidly extend the number of beds.

Conclusions: The performance of a quasi-market model against public health emergencies largely depends on integration between policymakers and balance between healthcare providers, which require clear regulation. Reducing institutional fragmentation between levels of governance, improving the coordination of healthcare facilities and adopting telemedicine technologies are means by which healthcare networks could strengthen their resilience against future outbreaks.
\end{abstract}

Key words: administered competition, COVID-19, Italy, Lombardy, quasi-market systems, crisis management

Address for correspondence: F. Pennestrì, IRCCS Istituto Ortopedico Galeazzi, Via Riccardo Galeazzi 4, 20161 Milano, Italy. E-mail: federico. pennestri@grupposandonato.it

https://doi.org/10.21101/cejph.a6533

\section{INTRODUCTION}

The Region of Lombardy was the most severely affected by the outbreak of COVID-19 in Italy.

Lombardy is similar in demographic characteristics to some of the largest European metropolitan areas (1), with a population of more than 10 million inhabitants, a density of approximately 418 inhabitants per $\mathrm{km}^{2}$, three international airports and significant rates of active mobility both for business and healthcare needs. In particular, the high volumes of acute care provided in Lombardy largely result from the characteristics of the local healthcare system, which represents an isolated case of administered competition (the so-called "quasi market") (2) within an otherwise centrally-driven, taxation-based Beveridge system, the Italian National Health Service (3).

\section{A System within the System}

The National Health Service (Italian acronym SSN) was introduced in 1978 in the form of a taxation-based, public-run Beveridge system, similar to the British National Health Service (NHS), in order to provide the entire population with universal healthcare coverage. Fourteen years after the SSN was established, it became clear that centralized control was unable to meet the needs of delivering care efficiently and effectively to the entire population, largely because of the heterogeneous Italian 
demography, geography, social fabric, culture, and distribution of healthcare facilities within and between regions. Substantial revisions were introduced to the SSN in the early 1990 s, creating the foundations for the progressive diversification of regional systems, which were given responsibility for meeting universal healthcare coverage goals set at the national level while taking responsibility for self-administration and performance management.

Following the national reform of the 1990s, Lombardy opted for a quasi-market healthcare system. The concept of "quasimarket systems" was developed in the early 1990s, introducing administered or managed competition in social activities (2). A quasi-market is a public sector institutional structure that is designed to reap the supposed efficiency gains of free markets without losing the equity benefits of traditional systems of public administration and financing (3). In health care, the aim of the model is to incentivise higher quality of care, promote the freedom of patients to choose where they prefer to be cared for, reduce costs by means of competition, and ensure fair access regardless of individual financial capacity.

Lombardy's choice was influenced by its local entrepreneurial and social fabric, as the region is characterized by a remarkable presence of private and non-profit organizations providing health and social care (the so-called subsidiarity). These organizations share developed organizational connections, are sometimes representative of the cultural roots within Lombardy and are often preferred by the local population for care provision. In response to the national reforms of the 1990s, Lombardy leveraged these pre-existing care facilities to organize a consistent health and social network funded with public resources by the SSN.

Managed competition between public and private providers has helped Lombardy to become one among only five Italian regions fully compliant with national healthcare goals set by the SSN (4). In addition to this, it has contributed to the development of an excellent hospital network including 18 research and teaching hospitals (4 are public and 14 are private), which represent $40 \%$ of the national total. Lombardy's hospital network also delivers benefits for Italy more widely: $11 \%$ of the patients hospitalized in Lombardy come from other regions where they cannot access the same treatment due to waiting lists, less advanced technologies or different expertise. In some private hospitals, non-Lombardy patients can reach $20 \%$, with peaks between $30-50 \%$ for certain specialties (5).

In addition to clinical excellence, indicators of patient experience position the Lombardy healthcare system as the second most responsive in terms of communication from professionals, levels of privacy, dignity, waiting times, and quality of structures (6). In the field of emergency care, the region introduced a dedicated institution "AREU", based on cooperation between public and private facilities, which the European Emergency Number Association ranked as the most efficient in 2016.

\section{The First COVID-19 Wave}

In the context of the COVID-19 outbreak, the case of Lombardy (7-9) raised criticisms because the large number of private providers was held responsible for providing insufficient support during the epidemic (10-12). A quasi-market system never had to face such a large scale, sudden epidemic with no preventive or therapeutic treatments available, as basic public health measures such as hand washing, use of individual protective equipment, social distancing, and quarantine were the only precautions to rely on, which were soon made mandatory both in Southern and Central Europe $(1,13)$. In these conditions, the ability of the healthcare system to be responsive out of the resources already available was essential. Therefore, the COVID-19 epidemic provides the context for a natural, though tragic, experiment to understand the resilience and responsiveness of a specific healthcare model against a sudden public health emergency.

This manuscript aims to review the strengths and weaknesses of Lombardy's response during the first wave of the COVID-19 epidemic, taking advantage of the direct experience of professionals from Lombardy's private medical sector and from independent national and international policy analysts, in order to analyze whether the model influenced crisis management and describe which policy arrangements could help to contain future outbreaks.

\section{MATERIALS AND METHODS}

Comparisons were made between the Region of Lombardy and the Region of Veneto, which are often used to highlight opposite approaches towards the epidemic, as the first COVID-19 certified deaths were reported there (7-9). Although both Lombardy and Veneto adopted strict measures of social distancing and early retail closures, they opted for different management strategies for patients with suspected or confirmed infections. In particular, the Region of Veneto aimed to contain the spread of the virus outside hospitals by:

- extensive proactive testing of symptomatic and asymptomatic cases;

- cascade screening to promote early identification of potential COVID-19+ individuals among a patients' social network (i.e., parents and neighbours);

- strong emphasis on home diagnosis and care, providing swabs and treatments directly at home;

- systematic monitoring of essential workers for sustenance of the community (i.e., healthcare professionals, supermarket cashiers, pharmacists, and protective service staff).

The Region of Lombardy, in contrast, aimed to contain the spread of the virus mostly within hospitals by:

- systematically testing only patients admitted to hospitals;

- extending the ICU network to host more critical patients;

- dividing COVID-19-dedicated wards and hospital pathways from those dedicated to other patients and diseases;

- setting up a dedicated phone number to help potential or paucisymptomatic patients who could stay at home (14).

Building on the epidemiological data made available by the Civil Protection Agency, the Ministry of Health, and the regions (15), it was possible to compare some relevant trends between Lombardy and Veneto; analyze them in light of progressive normative and organizational interventions; and support the international quest for investigating the performance of different healthcare models in specific contextual circumstances (16). 


\section{RESULTS}

Preliminary evidence from national reports and peer-reviewed literature highlighted the variation in the spread of COVID-19 between Italian regions $(10,17)$. National data from June 4th confirmed the high variation in infections and deaths, ranging from $8 \%$ infections and $5 \%$ deaths of the total number of cases reported in low areas of diffusion like Sicily and Basilicata to $75 \%$ infections and $83 \%$ deaths in areas of high diffusion in the North (17). On April 15, Lombardy accounted for 37\% of the national cases and $53 \%$ of deaths, three times those of Veneto and six times those of the rest of the country (18). At the end of the lockdown, Lombardy had a number of COVID-19 patients greater than the total sum of cases in three other large northern regions (Piedmont, Emilia Romagna, Veneto) (19). Indeed, the number of COVID-19 certified cases in the Region of Lombardy on May 18 was nearly four times higher than in the Region of Veneto (Fig. 1), where the first two deaths were identified on February 22. Figure 1 shows the spread of SARS-COV-2 infections and COVID-19 deaths in Lombardy and Veneto, building on data from the Italian Civil Protection Agency, distributed for eight index-events: the first data available in the Civil Protection database (February 24); the Prime Minister's Decree proclaiming national lockdown, and the National Decree Law on the "Enhancement of the National Health Service in relation to the COVID-19 pandemic", which asked the

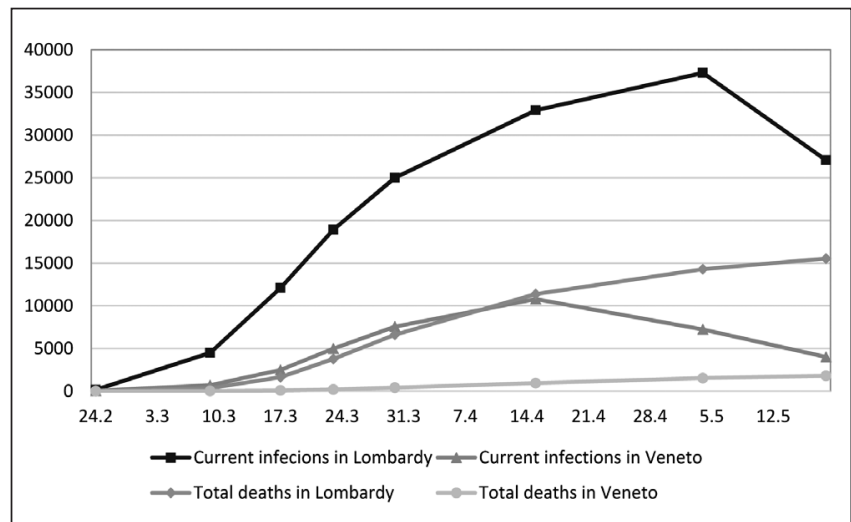

Fig. 1. Spread of SARS-COV-2 infections and COVID-19 deaths in Lombardy and Veneto from 24 February 2020-18 May 2020.

Data source: Ministry of Health and Civil Protection Agency

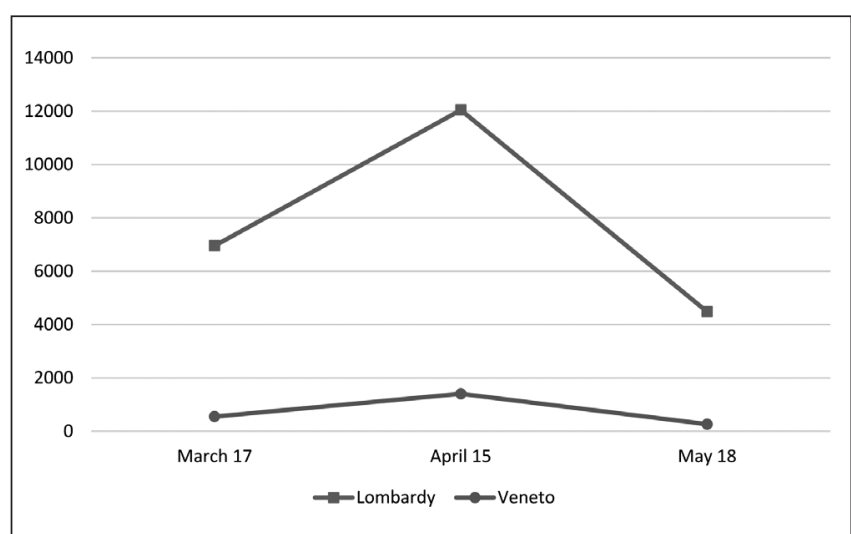

Fig. 2. Hospitalized patients from 17 Mar 2020-18 May 2020. Data source: Ministry of Health and Civil Protection Agency

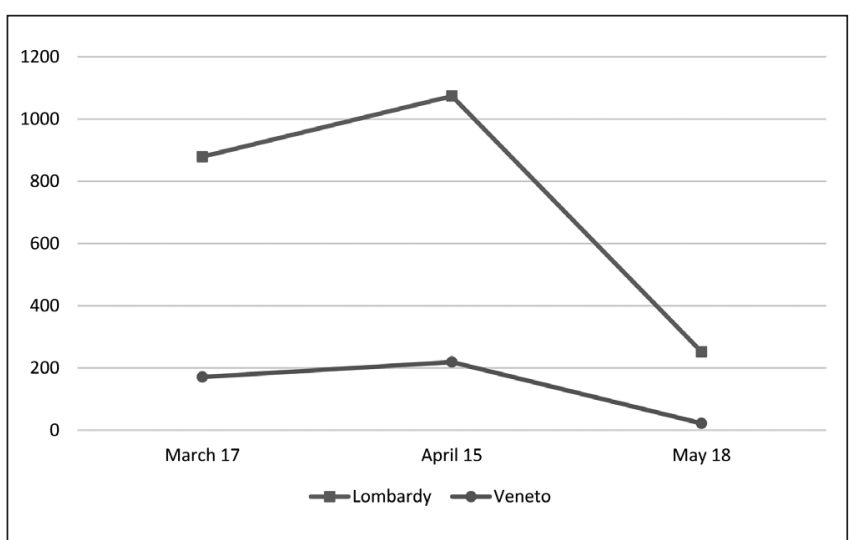

Fig. 3. Patients admitted to ICUs from 17 March 2020-18 May 2020.

Data source: Ministry of Health and Civil Protection Agency

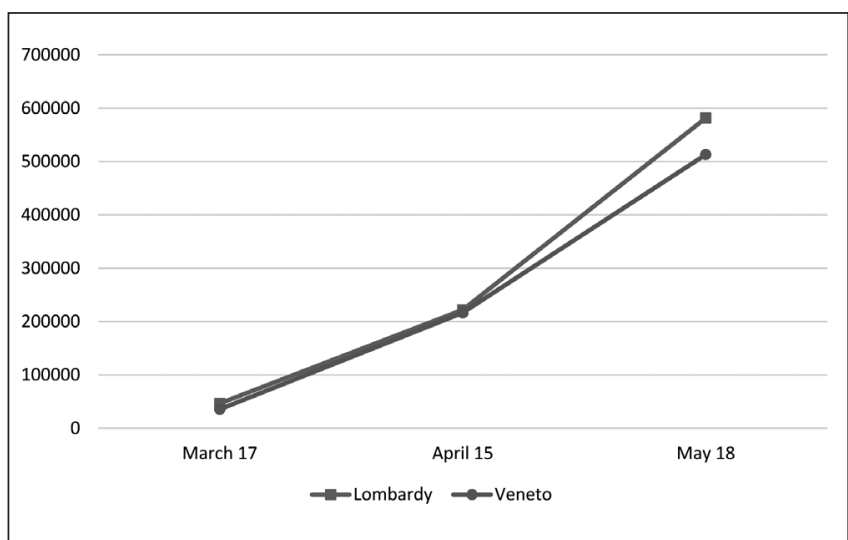

Fig. 4. Swabs performed from 17 March 2020-18 May 2020. Data source: Ministry of Health and Civil Protection Agency

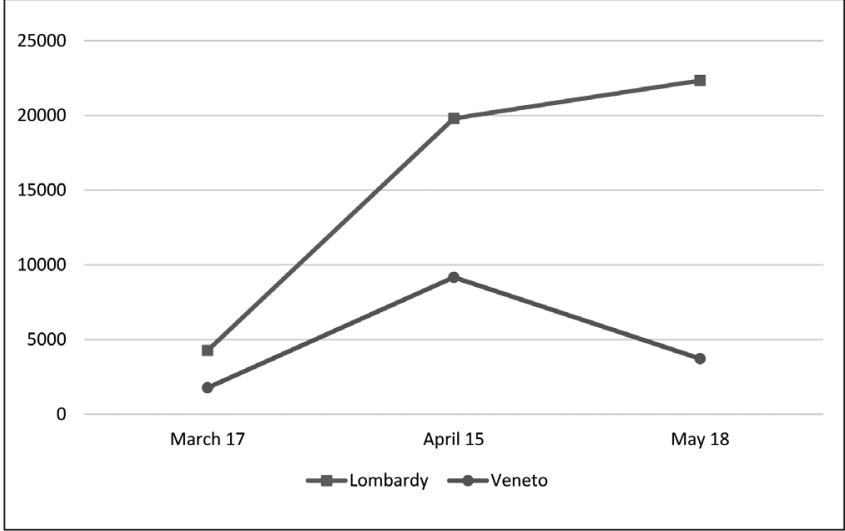

Fig. 5. Citizens in home isolation from 17 March 2020-18 May 2020.

Data source: Ministry of Health and Civil Protection Agency

regions to activate the Special Units for the Continuity of Care (Italian acronym USCAs) (March 9); the Ministry of Health periodical reports (March 17, April 15, May 18); the activation measure of USCAs in Lombardy (March 23); the activation measure of USCAs in Veneto (March 30); the Prime Minister's Decree proclaiming partial reopening (published on April 26, in force since May 4); the Prime Minister's Decree proclaiming further reopening (published on May 17, in force since May 18). 
Figures 2 and 3 show the number of hospitalizations and patients admitted to intensive care units (ICUs) according to the reports published by the Ministry of Health on March 17 (approximately one week after the national lockdown), April 15 (after the USCAs were activated at a local level) and May 18 (the end of national lockdown).

Building on the same database, Figure 4 represents the number of swabs performed by the regions on the local population and Figure 5 shows the number of individuals in each region that were in home isolation.

\section{DISCUSSION}

\section{Factors that May Have Influenced Lombardy's Early Experience with COVID-19}

The pronounced impact of the COVID-19 outbreak on the Region of Lombardy in comparison to the rest of Italy may have its roots in several possible reasons including: Lombardy being at the epicentre of the epidemic (9) without any effective treatments except from basic hygiene measures (1); Lombardy being one of the highest density metropolitan areas in Europe (1); the low air quality in Lombardy, which may explain the difference in COVID-19 spread and impact in comparison to the South but not, for instance, in comparison to Veneto (20); a large influx and efflux of people into and out of Lombardy because of its role as a thriving global centre for commercial and industrial business, with many people daily commuting to work and three international airports; the relatively high prevalence of singleunit families and elderly people living alone, especially in Milan, which may hamper the delivery of first aid and timely care (21); and the acute event of Bergamo, a neighbouring city, hosting a UEFA Champions League match two days after the first deaths were reported, with half the population of the city celebrating the victory overnight (22).

According to critics, however, this variation can also be explained by specific policy interventions more or less directly associated with the peculiar healthcare system of Lombardy, which either positively or negatively contributed to the approach taken during the epidemic. Indeed, the case of Lombardy generated a roar well beyond national boundaries $(1,7,8)$, raising severe criticisms to which followed equal reactions.

The main criticisms of Lombardy's healthcare system were that the high presence of private providers was considered responsible for providing poor support against such a violent, sudden public health emergency; and the managed competition system historically favouring investments in the hospital network (which is more remunerative to for-profit providers) rather than in community care. The gradual erosion of community care could have further increased hospitalization rates as a consequence of preventable complications and readmissions, putting hospitals and acute care at the centre of the healthcare system rather than prevention and extra-hospital patient management $(10,11)$. A letter from the regional medical society underlined how "in face of an excellent intervention on the enhancement of intensive and semi-intensive therapies, made possible by the commitment and sacrifice of doctors and other health professionals, the absence of effective strategies of community care were evident" (11).

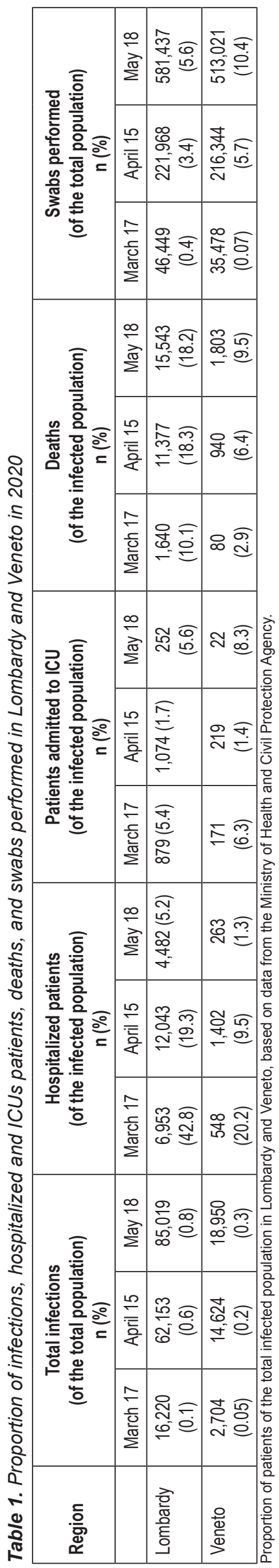


Performing diagnostic swabs only on hospitalized patients may have biased the epidemiological monitoring of the disease, as potential patients could prefer to stay home for fear of being admitted to hospitals and increase their exposure to the infection; the overload of the emergency telephone line may have prevented the prompt hospitalization of patients who were not yet critical; the rapid saturation of hospitals forced the discharge of paucisymptomatic elderly patients to nursing homes, which contributed to the spread of COVID-19 among residents and caregivers, further facilitated by the insufficient provision of personal protective equipment to health and social care professionals in these settings (11) (although the responsibility was here attributed to the National Government) (23). Moreover, though Lombardy was among the first regions to activate USCAs in order to provide home care for patients, the number of units activated was not sufficient to meet the need within the population. Following the conservative approach recommended by the Government also contributed to Lombardy taking an approach to "follow rather than prevent" the spread of the virus $(8,10)$.

Many critics explain this outcome as the consequence of the perverse incentives triggered by managed competition systems, as private providers can choose which services they prefer to deliver, and which patients to treat. This phenomenon - known in the literature as "cherry picking" or "cream skimming" (3) - has been attributed to quasi-market systems since the introduction of standardized payments like diagnosis-related groups (DRGs) (3), because once a standard remuneration programme is fixed, private providers are incentivized to focus on those treatments which maximize their profit, such as high volume procedures requiring short hospitalization and clear, measurable outcomes, most of which are delivered in hospitals; and to avoid treatments which require long term care associated with unclear recovery and sometimes low remuneration rates, such as primary and intensive care. Critics highlight that the lack of home care directly resulted from a disinterest of private providers to invest in lowremuneration activities, which they say also explained why the Lombardy ICUs network ( 8.5 beds per 100,000 inhabitants) was undersized in comparison to Emilia Romagna (another northern region which is a leader in health care) and Veneto (10 beds per $100,000)$. From their point of view, this is why Lombardy had experienced further organizational delays in order to set up an adequate response for critical patients (10).

The criticisms of Lombardy's quasi-market system raised prompt replies from policymakers, analysts, and healthcare professionals. A common observation was that any suboptimal outcome in the management of the epidemic needs to be contextualized in light of the sudden outbreak of the virus, whose spread was facilitated by a favourable epidemiological environment (due to the large population, the second highest density in Italy, busy commercial trade, and the high prevalence of elderly individuals with chronic conditions). Compared to Veneto, Lombardy has almost double the population both in quantity (approximately 10,060,000 vs. 4,906,000 inhabitants) and in density (approximately 418 vs. 265 per $\mathrm{km}^{2}$ ); compared to equivalent socio-demographic contexts on a global scale, a "Lombardy case" did not occur in terms of a specific mortality excess, and the rapid adaptation of the hospital network played a decisive role in preventing an even worse outcome (1). During the epidemic, policymakers and staff had to take decisions without evidence and time, taking respon- sibility for suboptimal choices (24). In these circumstances it is normal to take full advantage of what is available (in Lombardy's case, a strong hospital network) and eventually change strategy post-crisis. Combining data represented in Figure 4 with data illustrated in Table 1, it is clear that the absolute number of swabs performed in Lombardy was greater than in Veneto, but Veneto swabbed a greater proportion of its population. The net increase in swabs performed by both regions from the second half of April onwards may be due to the increase in home-isolated patients and the decrease in hospitalizations around the same period, which may, in turn, be interpreted as the attempt to keep as many patients monitored at home as possible, with the Lombardy trying to downsize its first hospital-oriented approach (Fig. 5). This would also be consistent with the strengthening of extra-hospital care after the outbreak and supported by the activation of USCAs on March 23 (although the quantity of units was still lower than the number planned on April 15) (10). Furthermore, being the first region in Italy and one of the first in Europe to be affected by the COVID-19 outbreak, Lombardy was starting from scratch and was not able to benefit from therapeutic protocols against the virus that were developed later. Two months earlier, for instance, a meningococcal infection outbreak was effectively managed through the cooperation between hospitals and community care professionals, made possible by validated protocols and treatments (25). Then, if we view the Lombardy experience in another way, it is precisely because of preliminary hospital experimentation of COVID-19 treatments under safe conditions (hydroxychloroquine, cortisone, heparin, antivirals, antibiotics for secondary infections) that other regions in Italy and across Europe could provide similar solutions directly at home, which also explains why USCAs have become more effective over time (9).

A second observation is that crisis management was not affected by cherry picking. The number of intensive care wards available in the region (113) is aligned with the highest range required by national regulation, and a difference of 1.5 beds per 100,000 inhabitants (as compared with other highly performing northern regions such as Veneto and Emilia Romagna) is unlikely to constitute cherry picking at a systemic level (9). Before the epidemic, private ICUs in Lombardy were $30 \%$ of the total $(270$ beds), with a similar percentage in private beds available for acute care (29.4\%). In the midst of the emergency (March 13-30), private beds increased to $484,28 \%$ of the total, and private acute beds dedicated to COVID-19 patients increased from 2,621 to $4,975,40 \%$ of the total. The quick response of the private sector to meet sudden public health needs - by increasing the availability of wards for severe COVID-19 patients - allowed public hospitals to reorganize themselves to cope with the emergency. The faster decision-making procedures of private hospitals offered a receptive channel to bottom-up support from society rather than undermining solidarity (5). In Lombardy, high-volume, private metropolitan hospitals reshaped entire ICU facilities in a handful of days, building up new units from private donations (26); the sacrifices of professionals who put their life at risk and imposed long-term self-isolation from their families were equal in public and private hospitals; at the time of writing, the first dedicated COVID-19 rehabilitation unit is run by a private hospital which rehabilitated 150 patients in two months. Moreover, the same Regions of Veneto and Emilia Romagna also had to rapidly increase the number of ICUs available to face the early outbreak of the 
epidemic, therefore, the dearth of intensive care beds seems not to be related to the peculiar healthcare system in place.

The first wave of the epidemic was difficult everywhere. For Lombardy, this difficulty was compounded by the fact that it was one of the first regions in Europe to face COVID-19. Lombardy's ability to turn regular wards and professionals into COVID-19 specialized units and care takers during the first wave of the epidemic can be seen as a case of "positive deviance", which provided a baseline that helped to inform best practice for crisis management across the country.

\section{Lessons Learned}

Among the " 12 lessons learned from the management of the coronavirus pandemic" (27), macro, meso and micro level recommendations, namely the need to reduce institutional fragmentation (i.e., between different levels of governance), improve the coordination of healthcare facilities (i.e., primary, intermediate and secondary care) and adopt telemedicine technologies are consistent with the case of Lombardy.

\section{Macro Level - Reducing Institutional Fragmentation}

The fragmentation between the Central Government and the regions was at the root of many suboptimal outcomes and operational delays in Lombardy and Italy more generally. For example, the decision to discharge patients to nursing homes, was undertaken provided patients were separated from other residents and all professionals taking care of them were given individual protective equipment (9). However, the provision of delayed, non-compliant devices from the Government pushed Lombardy to play catch up and required the region to discard and replace them within a few days to keep staff safe. Indeed, other regions faced similar problems which contributed to a "nursing home massacre" across the entire country (28).

The inefficient management of emergency equipment is a consequence of the institutional fragmentation brought forward in Italy in the early 2000s (29). While civil protection responsibilities belong to the region, the upgrade of validated protection equipment is the responsibility of the Government, and this has been delayed for over ten years. The risks posed by fragmentation are consistent with the Organization for the Economic Cooperation and Development (OECD) Revision of Healthcare Quality in Italy, which highlighted that fragmented care may undermine the excellence of healthcare professionals to the special detriment of frail patients with chronic conditions (30). Lombardy was the first region exposed to this particular problem in the context of the COVID-19 epidemic, with a violent and sudden outbreak. Extraordinary efforts from public and private healthcare professionals prevented a greater tragedy, and the lessons learned from Lombardy helped other regions to make necessary arrangements.

\section{Meso Level - Strengthening the Entire Healthcare System, Including Community Care, and Discourag- ing Cherry Picking}

Hospitals are organized to deliver reactive, disease-oriented care which may deliver excellent performance for acute, emergency situations, but not for proactive community approaches.
Although Lombardy followed government guidelines during the pandemic, the more proactive approach of Veneto seemed more appropriate in the context of the COVID-19 epidemic.

In order to strengthen community care, in 2015 the Region of Lombardy launched a reform of the entire health and social care network, investing in the same incentives that successfully strengthened secondary care from the late 1990s, namely managed competition between public and private providers. Care managers and community care networks were introduced for this purpose. Care managers are responsible for patient management across the entire healthcare journey in order to reduce the risks of healthcare fragmentation, avoid hospitalization, and provide coordinated healthcare pathways through a personal clinical manager, which can be the patient's GP or a specialist. Care managers are remunerated with a fixed, pay-per-coordination budget for each patient. The budget is based on clusters of average health and social care consumption associated with a certain type of patient, which is the equivalent of hospital DRGs for the management of chronic conditions outside hospitals (chronic-related groups - CReGs), and as such, is expected to provide proportionate incentives to the development of community care (21). The progressive reduction of such a disparity is likely to strengthen primary and community care services, thus improving the responsiveness of the system to future public health emergencies. At the time of writing, this process is under revision, and the COVID-19 pandemic is a further reason to accelerate the reform.

To achieve this within a quasi-market system requires prudential rules and clear requirements, which leave little room for negotiations during times of emergency (10). Choosing patients may be profitable for private providers, but this is of a little interest if the funder is a public institution since it is required to deliver universal care within a finite budget. As a confirmation of this, Lombardy has recently adopted measures to counter the drive towards cherry-picking by private providers, decreasing the remuneration of orthopaedic procedures of questionable value (e.g., surgical arthrodesis to cure low back pain) to one third in order to discourage inappropriate medicalization for the sake of profit (31). In primary, community and emergency care, a clear rule could be set to require not only the general provision of first aid and intensive care to obtain public funding, but also defining the minimum number of units needed (10).

\section{Micro Level - Better Use of Technology}

The 2015 reforms advocated for investments in telemedicine technologies in order to better meet patients' needs, improve quality of life, improve healthcare accessibility, reduce waiting lists, reduce hospital visits, and facilitate information sharing between the hospital and the community. Indeed, preliminary experience of integrated pathways for patients with hypertension, diabetes, congestive heart failure, and/or chronic obstructive pulmonary disease (COPD) demonstrated improved therapeutic compliance and reduced inappropriate access to hospitals and first aid (21). Telemedicine could provide added benefits to the management of COVID-19 patients directly at home, as permanent connections between GPs and their patients could be more beneficial than the impersonal, and potentially overburdened, emergency line. In August 2020, the Region of Lombardy formally approved the 
guidelines to use telemedicine for the benefit of patients to be monitored remotely.

\section{CONCLUSIONS}

While competition can promote excellence, it could also compromise the public health if it is not regulated properly. Inadequate protection of the community, as a result of disproportionate investments in hospitals relative to community care (11) and insufficient funding of home care and ICUs as a result of cherry picking from private providers (10), was at the centre of the debate about the role managed competition played during the COVID-19 epidemic in Lombardy.

However, the wholesale condemnation of Lombardy's quasimarket system is not fair, considering that Lombardy was one of the first regions to be hit in Europe and did not have access to evidence on best practice for diagnostics or treatment; Lombardy had no choice but to face the emergency with resources available, its private providers contributed significantly to the containment of the outbreak; and institutional fragmentation is beyond the responsibility of the region. Lombardy learned several lessons from the COVID-19 epidemic, which does not necessarily put into discussion the administered competition model itself but requires clear rules to balance its benefits and risks.

\section{Implications for Policy and Practice}

- Quasi-market systems may trigger cherry picking from private providers that may prefer the provision of highly remunerated healthcare regardless of their benefit to public health; disproportionate investments in acute care may undermine the effectiveness of proactive community approaches in case of a sudden public health emergency such as the COVID-19 epidemic.

- Setting clear minimum requirements to be respected by private providers to obtain public funding can help to identify and tackle cherry picking episodes in advance; once a clear regulation is provided by the administered competition manager, private providers can promote solidarity, while also contributing to crisis management with quick, responsive support.

- In case of a national public health emergency, the fragmentation between policymakers (the Central Government and local healthcare systems) as well as the fragmentation among the multiple institutions involved in healthcare provision (hospitals, intermediate and community care) can contribute to suboptimal outcomes and operational delays in the management of a sudden crisis. Strengthening the integration of healthcare and keeping patients out of hospitals as much as possible is a key investment to prevent rather than follow the spread of a virus.

\section{Conflict of Interests}

None declared

\section{REFERENCES}

1. Signorelli C, Odone A, Gianfredi V, Bossi E, Bucci D, Oradini-Alacreu A, et al. The spread of COVID-19 in six western metropolitan regions: a false myth on the excess of mortality in Lombardy and the defense of the city of Milan. Acta Biomed. 2020;91(2):23-30.
2. Bartlett W, Roberts JA, Le Grand J, editors. A revolution in social policy: quasi-market reforms in the 1990s. Bristol: The Policy Press; 1998.

3. Garattini L, Padula A. Competition in health markets: is something rotten? J R Soc Med. 2019;112(1):6-10.

4. Ministy of Health. Monitoring essential levels of healthcare, the scores of all regions based on 2017 outcomes [Internet]. 2019 [cited 2020 Aug 26]. Available from: http://www.salute.gov.it/portale/news/p3_2_1_1_1.jsp? lingua $=$ italiano $\& m e n u=$ notizie $\& p=$ dalministero $\& i d=3582$. (In Italian.)

5. Merlino L. Healthcare in Lombardy: why the partnership between private and public providers which saved 28 thousand lives may be annoying [Internet]. Il Sussidiario; 2020 [cited 2020 Aug 26]. Available from: https://www.ilsussidiario.net/news/sanita-lombardia-pubblico-privatoecco-perche-da-fastidio-il-patto-che-ha-salvato-dal-covid-28milavite/2010934/. (In Italian.)

6. European House-Ambrosetti. Meridiano Healthcare Forum - 11th edition. Final report 2016 [Internet]. Rome: European House-Ambrosetti; 2016 [cited 2020 Aug 26]. Available from: https://www.ambrosetti.eu/ wp-content/uploads/Meridiano-Sanit\%C3\%A0-2016_RepordBASSA. pdf. (In Italian.)

7. Zangrillo A, Gattinoni L. Learning from mistakes during the pandemic: the Lombardy lesson. Intensive Care Med. 2020;46(8):1622-3.

8. Pisano GP, Sadun R, Zanini M. Lessons from Italy's response to coronavirus [Internet]. Harvard Business Review; 2020 [cited 2020 Aug 26]. Available from: https://hbr.org/2020/03/lessons-from-italys-response-tocoronavirus.

9. Merlino L. The case of Lombardy; hospitals, swabs, nursing homes: the false accusations dismantled one by one [Internet]. Il Sussidiario; 2020 [cited 2020 Aug 26]. Available from: https://www.ilsussidiario.net/news/ coronavirus-lombardia-ospedali-tamponi-rsa-le-false-accuse-smontateuna-per-una/2010759/. (In Italian.)

10. Gabanelli M, Ravizza S. Coronavirus, why so many deaths in Lombardy? Six inevitable questions [Internet]. Corriere della Sera; 2020 [cited 2020 Aug 26]. Available from: https://www.corriere.it/politica/20_aprile_15/ coronavirus-tutti-errori-lombardia-perche-cosi-tante-vittime- $487 \mathrm{~d} 0 \overline{\mathrm{cb}} 8$ 7e88-11 ea-9d1e-3b71 f043fc58.shtml. (In Italian.)

11. Federazione Nazionale degli Ordini dei Medici Chirurghi e Odontoiatri. FROMCeO Lombardia. New letter to the Lombardy healthcare leaders [Internet]. FNOMCeO; 2020 [cited 2020 Aug 26]. Available from: https://portale.fnomceo.it/fromceo-lombardia-nuova-lettera-indirizzata-aivertici-della-sanita-lombarda/. (In Italian.)

12. Federazione Regionale degli Ordini dei Medici Chirurgi e Odontoiatri della Lombardia. Circular no. 13 [Internet]. FROMCeO; 2020 [cited 2020 Aug 26]. Available from: https://portale.fnomceo.it/wp-content/ uploads/2020/03/Lettera-Covid19_-Avv.-Gallera_30032020-signed.pdf. (In Italian.)

13. Stř̌́žová Z, Bartůňková J, Smrž D. Can Wearing face masks in public affect transmission route and viral load in COVID-19? Cent Eur J Public Health. 2020;28(2):161-2.

14. Lumbreras C. Covid-19: how the region of Lombardy adapted its emergency response procedures [Internet]. EENA; 2020 [cited 2020 Aug 26]. Available from: https://eena.org/knowledge-hub/press-releases/covid19lombardy-emergency-response/.

15. Ministry of Health [Internet]. Rome [cited 2021 Mar 23]. Available from: http://www.salute.gov.it. (In Italian.)

16. Tynkkynen LK, Vrangbæk K. Comparing public and private providers: a scoping review of hospital services in Europe. BMC Health Serv Res. 2018;18:141. doi: 10.1186/s12913-018-2953-9.

17. Signorelli C, Scognamiglio T, Odone A. COVID-19 in Italy: impact of containment measures and prevalence estimates of infection in the general population. Acta Biomed. 2020;91(3-S):175-9.

18. Ministry of Health. Covid-19, situation report update at 15 April 2020 18.00 [Internet]. Ministry of Health: Rome; 2020 [cited 2021 Mar 23]. Available from: https://www.salute.gov.it/portale/nuovocoronavirus/ dettaglioNotizieNuovoCoronavirus.jsp? id $=4483$.

19. Ministry of Health. Covid-19, situation report update at 18 May 2020 18.00 [Internet]. Ministry of Health: Rome; 2020 [cited 2021 Mar 23]. Available from: https://www.salute.gov.it/portale/news/p3_2_1_1_1.jsp ?lingua $=$ italiano\&menu $=$ notizie $\& \mathrm{p}=$ dalministero $\& \mathrm{id}=47 \overline{7}$.

20. Fiasca F, Minelli M, Maio D, Minelli M, Vergallo I, Necozione S, et al. Associations between COVID-19 Incidence Rates and the Exposure to PM2.5 and NO2: A Nationwide Observational Study in Italy. Int J Environ Res Public Health. 2020;17(24):9318. doi: 10.3390/ijerph17249318.

21. Pennestrì F. Dalla cura al prendersi cura. From cure to care: Regione Lombardia welfare reform between fairness, universalism and sustainability. Politiche Sanitarie. 2017;18(3):113-27. (In Italian.) 
22. Boccia S, Ricciardi W, Ioannidis JPA. What other countries can learn from Italy during the COVID-19 Pandemic. JAMA Intern Med. 2020;180(7):927-8

23. Monaci S. Protective masks against coronavirus, the Lombardy charges the Civil Protection: they are useless [Internet]. Il Sole 24 Ore; 2020 [cited 2020 Aug 26]. Available from: https://www.ilsole24ore.com/art/ mascherine-coronavirus-lombardia-accusa-protezione-civile-inutiliADLL1OD. (In Italian.)

24. Camuffo A, Gambardella A, Soda G. Coronavirus, why at Harvard they were wrong [Internet]. Il Sole 24 Ore; 2020 [cited 2020 Aug 26]. Available from: https://www.ilsole24ore.com/art/coronavirus-perche-ad-harvardhanno-sbagliato-ADPrLEH. (In Italian.)

25. Stefanelli P, Fazio C, Neri A, Vacca P, Palmieri A, Ambrosio L, et al. Meningococcal C outbreak in Lombardy (2019-2020) [Internet]. Epicentro; 2020 [cited 2020 Aug 26]. Available from: https://www.epicentro. iss.it/meningite/focolaio-lombardia-2019-2020. (In Italian.)

26. Zangrillo A, Beretta L, Silvani P, Colombo S, Scandroglio AM, Dell'Acqua A, et al. Fast reshaping of intensive care unit facilities in a large metropolitan hospital in Milan, Italy: facing the COVID-19 pandemic emergency. Crit Care Resusc. 2020;22(2):91-4.

27. Forman R, Atun R, McKee M, Mossialos E. 12 Lessons learned from the management of the coronavirus pandemic. Health Policy. 2020;124(6):577-80.
28. Istituto Superiore di Sanità. National survey on Covid-19 contagion in residential and social-healthcare facilities: final report [Internet]. 2020 [cited 2020 Aug 26]. Available from: https://www.iss.it/documents/20126/0/Report_surveyFinale+RSA.pdf/4b14b829-5a07-24e9955a-4d4c9a7e4440?t=1592402115720. (In Italian.)

29. Gaudioso A. What are we learning (perhaps) about the National Health Service [Internet]. Cittadinanzattiva; 2020 [cited 2020 Aug 26]. Available from: https:/www.cittadinanzattiva.it/editoriale/salute/13161-cosa-stiamo-imparando-forse-sul-servizio-sanitario-nazionale.html. (In Italian.)

30. Organization for Economic Cooperation and Development. Italy: raising standards. OECD Reviews of Health Care Quality. Paris: OECD Publishing; 2014.

31. Gabanelli M, Ravizza S. Back pain business: too many unnecessary interventions. Only Lombardy says "stop" [Internet]. Corriere della Sera; 2019 [cited 2020 Aug 26]. Available from: https://www.corriere. it/dataroom-milena-gabanelli/artrodesi-business-mal-schiena-troppiinterventi-inutili-solo-lombardia-dice-basta/2533cbfa-053b-11ea-a1dfd75c93ec44da-va.shtml. (In Italian.)

Received September 18, 2020 Accepted in revised form March 23, 2021 